J. Dairy Sci. 96:6763-6774

http://dx.doi.org/10.3168/jds.2013-6713

(C) American Dairy Science Association ${ }^{\circledR}, 2013$.

\title{
Noninferiority trial comparing a first-generation cephalosporin with a third-generation cephalosporin in the treatment of nonsevere clinical mastitis in dairy cows
}

\author{
Y. H. Schukken, ${ }^{* 1}$ M. J. Zurakowski, ${ }^{*}$ B. J. Rauch, ${ }^{*}$ B. Gross, ${ }^{*}$ L. L. Tikofsky, $\dagger$ and F. L. Welcome ${ }^{*}$ \\ *Department of Population Medicine and Diagnostic Sciences, College of Veterinary Medicine, Cornell University, Ithaca, NY 14853 \\ †Boehringer Ingelheim Vetmedica Inc., 2621 North Belt Highway, St. Joseph, MO 64506
}

\begin{abstract}
The objective of this study was to evaluate the noninferiority of 2 intramammary treatments for nonsevere clinical mastitis. The 2 treatments were a first-generation cephalosporin (cephapirin sodium, 2 treatments 12 $\mathrm{h}$ apart) and a third-generation cephalosporin (ceftiofur hydrochloride, treatments once a day for $5 \mathrm{~d}$ ). A total of 296 cases on 7 farms met the enrollment criteria for the study. Streptococcus dysgalactiae was the most common bacterial species identified in milk samples from cows with mild to moderate clinical mastitis, followed by Escherichia coli, other esculin-positive cocci, Streptococcus uberis, and Klebsiella spp. Treatment was randomly allocated as either cephapirin sodium or ceftiofur hydrochloride via intramammary infusion according to label standards. Bacteriological cure was defined based on 2 posttreatment milk samples taken at 10 and $17 \mathrm{~d}$ after enrollment. Noninferiority of cephapirin relative to ceftiofur was shown for bacteriological cure of gram-positive cases and for clinical cure of all cases. Ceftiofur showed a significantly higher bacteriological cure in gram-negative cases. Treatments showed no significant difference in bacteriological cure of all cases and in time to exit from the study, where the absence of a difference does not imply noninferiority. Based on the findings from this study, farm-specific treatment protocols that differ for gram-positive and gram-negative cased may be developed.
\end{abstract}

Key words: mastitis, cephapirin, clinical trial, noninferiority

\section{INTRODUCTION}

Clinical mastitis (CM) is the most important disease of dairy cattle (Barkema et al., 1998; Gröhn et al., 2004). Farmers try to combat the disease and minimize the losses due to the disease by treating animals (Roberson,

Received February 19, 2013.

Accepted July 4, 2013.

${ }^{1}$ Corresponding author: yschukken@cornell.edu
2012). Several treatment options are available to treat CM; however, relatively few studies have compared the efficacy of available treatments under comparable circumstances (Waage, 1997; Deluyker et al., 1999; Taponen et al., 2003; Roberson et al., 2004; McDougall et al., 2007, 2010; Bradley and Green, 2009), and few of these studies were designed as noninferiority studies. Most published randomized controlled trials have been designed to determine whether a treatment is superior to an untreated control. However, efficacy compared with a negative control is not the primary interest of the dairy producer. It can be argued that comparison with existing treatments that are on the market is of more value for day-to-day decision making (Roberson, 2012). Also, studies that aim to demonstrate equivalence or noninferiority of treatments should be used when there are ethical concerns about leaving animals untreated (Schukken and Deluyker, 1995; Piaggio et al., 2006; O'Connor et al., 2010). Equivalence or noninferiority is particularly valuable and valid when there are advantages such as reduced costs, reduced dosing frequency, or improved safety of one product compared with a reference product (Piaggio et al., 2006; Powers, 2008). In the United States, placebo or no treatment controlled trials are the norm for registration of products (US FDA-CVM, 1996), whereas in the European Union, a positive control trial is recommended for registration of products in their market area, unless a placebo or no treatment control can be justified (European Medicines Agency, 2009). Throughout the world, several intramammary products for the treatment of CM in dairy cattle contain cephalosporins. Four generations of cephalosporins have evolved, all of which contain the $\beta$-lactam sub-structure first found in penicillin. The mastitis treatment products on the US market fall in the first and third cephalosporin generations. First-generation cephalosporins generally have a gram-positive spectrum with limited gramnegative activity (Guérin-Faublée et al., 2003; Pfeifer et al., 2010), whereas third-generation products have a broader spectrum of activity (Hornish and Kotarski, 2002). For this reason, there is a specific interest in 
the efficacy of third-generation cephalosporins against gram-negative organisms (Erskine et al., 2002; Wenz et al., 2005; Schukken et al., 2011).

Although gram-negative organisms are an important cause of CM on well-managed dairies (Erskine et al., 1988; Barkema et al., 1998; Olde Riekerink et al., 2008), gram-positive organisms such as Streptococcus uberis, Streptococcus dysgalactiae, and CNS remain present in a high number of treated mastitis cases (Apparao et al., 2009). Further, CM with culture results of "no growth" may represent 30 to $40 \%$ of cases (Olde Riekerink et al., 2008; Lago et al., 2010). Therefore, third-generation cephalosporins may not necessarily have an easily identifiable advantage over first-generation cephalosporins on all farms.

Even more, concerns over the use third- and fourthgeneration cephalosporins in food animals may eventually result in a more restrictive use of these antibiotics (Scientific Advisory Group on Antimicrobials of the Committee for Medicinal Products for Veterinary Use, 2009). Recently, the US Food and Drug Administration issued an order that prohibits the extra-label use of cephalosporin drugs (specifically excluding cephapirin) in cattle and other species (http://www.gpo.gov/fdsys/ pkg/FR-2012-01-06/pdf/2012-35.pdf). Similar or more restrictive use of third- and fourth-generation cephalosporins is anticipated in European countries (Scientific Advisory Group on Antimicrobials of the Committee for Medicinal Products for Veterinary Use, 2009). Hence, despite the potential benefits of third-generation cephalosporins over first-generation cephalosporins (Schukken et al. 2011), first-generation cephalosporins may eventually be more easily accepted in the dairy industry.

In this study, we compared the treatment efficacy of a 1-d treatment (2 doses at a 12-h interval) with the test product containing a first-generation cephalosporin (cephapirin) to the reference treatment of 5-d oncea-day treatment of a third-generation cephalosporin (ceftiofur). The objective of the trial was to evaluate whether noninferiority of the test product against the reference product could be established.

\section{MATERIALS AND METHODS}

The study was conducted on commercial dairy farms in New York State between December 2010 and September 2011.

\section{Study Design}

The study design for this treatment comparison study was a noninferiority study. Proving equality of treatments is logically impossible, so a pre-stated margin of noninferiority $(\Delta)$ needs to be defined (Piaggio et al., 2006; O'Connor et al., 2010). In noninferiority studies, the null hypothesis is that one treatment is inferior to the reference product, and the alternative hypothesis is that the new treatment is not inferior by more than the predefined margin $(-\Delta$; Piaggio et al., 2006). Thus, rejecting the null hypothesis $\left(\mathrm{H}_{0}\right)$ results in acceptance of the alternative hypothesis $\left(\mathrm{H}_{\mathrm{A}}\right)$ that the new product is noninferior to the reference product, more formally written as

$$
\begin{gathered}
\mathrm{H}_{0}:\left[P_{\text {cure }}(\text { cephapirin })-P_{\text {cure }}(\text { ceftiofur })\right] \leq-\Delta \\
\mathrm{H}_{\mathrm{A}}:\left[P_{\text {cure }}(\text { cephapirin })-P_{\text {cure }}(\text { ceftiofur })\right]>-\Delta,
\end{gathered}
$$

where $P_{\text {cure }}$ is the probability of cure and $\Delta$ is the noninferiority margin. In Figure 1, the principle of a noninferiority study is shown and the possible decisions based on hypothetical study outcomes are explained (adapted from Piaggio et al., 2006).

\section{Sample Size Determination}

The required sample size was calculated using the confidence interval (CI) approach, considering where the CI for the treatment effect lies with respect to both the margin of noninferiority, $\Delta$, and a null effect (treatments are assumed a priori to show equal cure risks). Selection of $\Delta$ is often based on results of negative (or placebo) controlled studies, on the basis that $\Delta$ will be no more than half the effect expected from a superiority study (Piaggio et al., 2006; Powers, 2008). Sample size was calculated assuming that the ceftiofur cure risk was approximately $70 \%$ (Schukken et al., 2011) and a statistical significance of $5 \%$ and power of $80 \%$ were chosen. For this study, we defined the acceptable difference in cure, the margin of noninferiority $(\Delta)$, as 0.15 . The choice of the noninferiority margin was based on a recent study in which ceftiofur-treated cows with mild or moderate CM caused by gram-negative organisms showed a $35 \%$ higher bacteriological cure compared with untreated controls (Schukken et al., 2011). The noninferiority margin of 0.15 is less than half this effect estimate from a superiority study. The same noninferiority margin has been used and suggested in other CM studies (Schukken and Deluyker, 1995; Deluyker et al., 1999). This choice of noninferiority margin resulted in an estimated sample size per group of 110 cases. The total study size is then twice this number at approximately 220 cases. Sample size calculations were performed with the use of StudySize 2.0.4 (Creostat HB, www.creostat.com). To allow for animals that were culture negative at first detection of $\mathrm{CM}$, the objective was to enroll 300 cows in the study. We thereby 


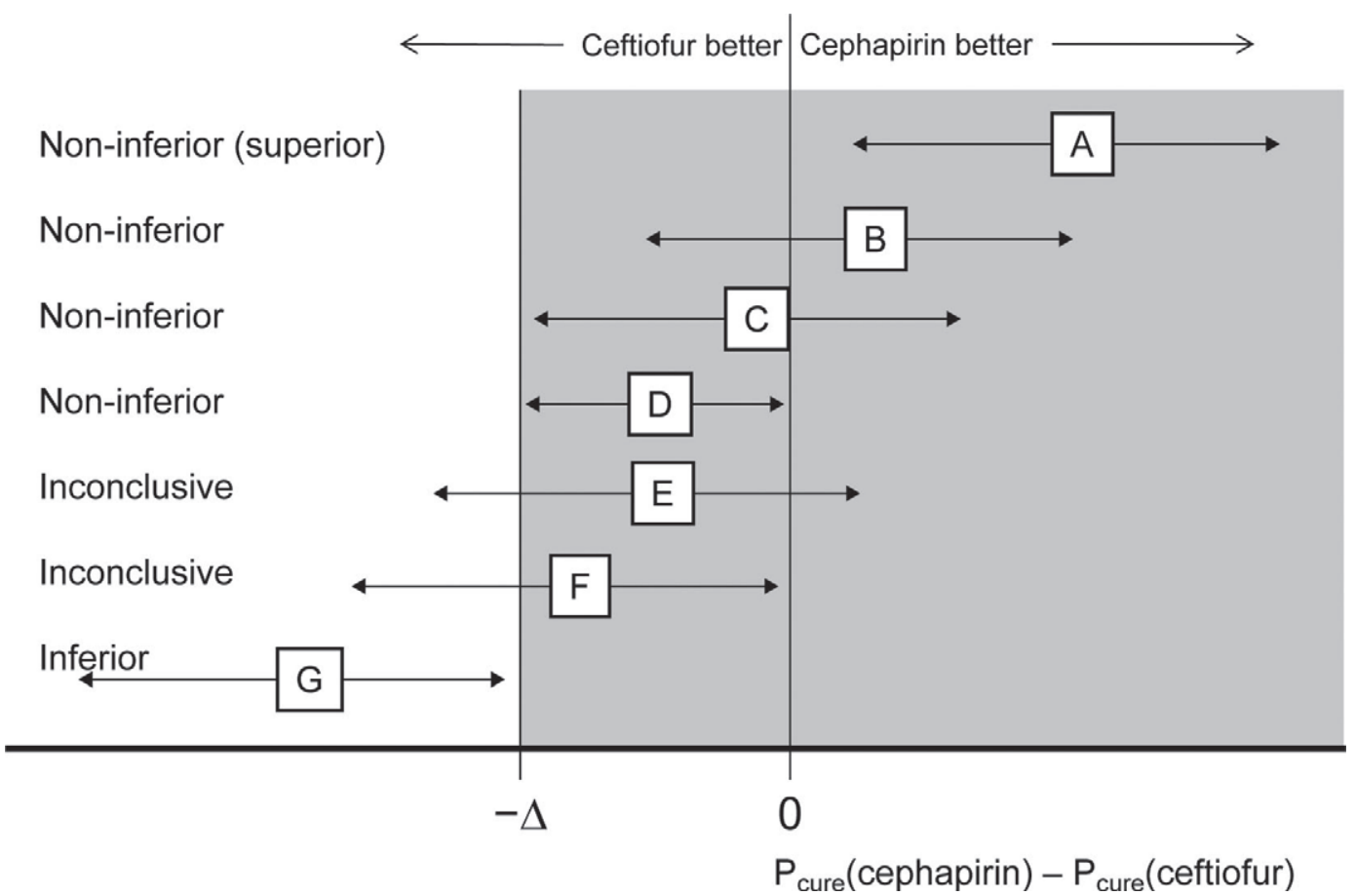

Figure 1. Principle and possible outcomes of a noninferiority trial. Arrowheads indicate $95 \%$ CI; shaded area indicates zone of noninferiority of cephapirin relative to ceftiofur. (A) If the CI lies wholly to the right of zero, cephapirin is noninferior and might be claimed as superior; (B) and $(\mathrm{C})$ if the CI lies to the right of the noninferiority margin $(-\Delta)$ and includes zero, cephapirin is noninferior; (D) if the CI lies wholly to the right of $-\Delta$ and wholly to the left of zero, cephapirin is noninferior using the predefined noninferiority margin $(-\Delta)$, but it is also inferior in the sense that cure with cephapirin is significantly less than the cure obtained with ceftiofur; (E) if the CI includes $-\Delta$ and zero, the result regarding noninferiority is inconclusive; $(\mathrm{F})$ if the CI includes $-\Delta$ and is wholly to the left of zero, ceftiofur is significantly better but the result is inconclusive regarding possible inferiority of magnitude $\Delta ;(\mathrm{G})$ if the CI is wholly below $-\Delta$, cephapirin is inferior to ceftiofur. Adapted from Piaggio et al. (2006).

assumed that at least 220 cows would show complete data.

\section{Inclusion Criteria for Farms and Cows}

Farms were eligible for inclusion in the study when the herd size was at least 200 cows, milked twice a day, participated in monthly DHIA testing including individual SCC testing, kept accurate records of CM cases, and were interested in participating in the study and able to collect data throughout the trial.

Cows were eligible for inclusion in the study when they were in parity 1 to 7 , were more than $25 \mathrm{~d}$ from anticipated dry-off date, had experienced no CM in the last $30 \mathrm{~d}$ and had received no treatment with antibiotics for another disease in the last $30 \mathrm{~d}$, were not enrolled in the study previously, had only one quarter with CM, and were not clinically classified as severe (see below).

\section{Clinical Severity Score}

The clinical scoring system to classify CM cases based on clinical severity that was used in this study was proposed and evaluated by Wenz et al. (2001,
2006). In addition to abnormal milk, this system is based on measurement of rectal temperature, hydration status, and clinical attitude. Severity of clinical signs was scored as mild, moderate, or severe. Only cows with a mild or moderate score were included in this study. A score of mild was assigned when the milk was grossly abnormal and no other local or systemic signs of inflammatory disease were seen; a score of moderate was assigned when the milk was grossly abnormal and there was firmness or swelling of the affected mammary gland, but none or only one of the systemic signs of inflammatory disease were seen. A score of severe was assigned if the milk was grossly abnormal, there was firmness or swelling of the affected mammary gland, and at least 2 of the following systemic disease signs were seen: rectal temperature $\geq 39.5^{\circ} \mathrm{C}\left(103^{\circ} \mathrm{F}\right)$, hydration score showing moderate to marked enophthalmos, and attitude score showing signs of marked depression (Wenz et al., 2001, 2006).

\section{Treatment Protocols and Randomization}

The 2 treatments in the study were (1) treatment according to label of ToDAY (Boehringer Ingelheim, St 
Joseph, MO), comprising 2 treatments of a 10-mL disposable syringe containing $200 \mathrm{mg}$ of cephapirin sodium per syringe at an interval of $12 \mathrm{~h}$; and (2) treatment with Spectramast (Zoetis, Kalamazoo, MI) once a day for $5 \mathrm{~d}$ with a $10-\mathrm{mL}$ disposable syringe containing 125 mg of ceftiofur hydrochloride per syringe. Spectramast has a flexible treatment duration for treatment up to 8 $\mathrm{d}$ on its label, and the 5 -d treatment was chosen based on our previous study (Schukken et al., 2011). When cows were diagnosed with CM, the study manager on the farm completed an enrollment form and when a cow met the enrollment criteria, randomization into 1 of 2 treatments took place. Randomization took place through the opening of a numbered envelope. The envelope contained detailed treatment instructions and treatment forms. Envelopes were accounted for and any deviation from the numbering scheme was noted and investigated. After establishing the treatment protocol, animals were sampled and treatment was initiated.

\section{Data Quality}

Sampling and clinical data collection were done by farm staff. Farm staff was trained to identify mastitis, enroll cases, take samples, fill out paperwork, and continue to monitor animals with clinical disease scores and repeat sampling for bacteriological culture. Farms were visited on a regular basis and at least monthly. The herd managers at the participating farms were continuously provided feedback with regard to their data quality. Inaccuracies or uncertainties were resolved with the herd manager as far as possible. All data were entered into a database and checked for internal logic and outliers. All flagged data points were resolved through further investigation. Decisions on eligibility and inclusion in the study and data analysis were documented and signed by the first author (YHS).

\section{Flow of Events for a Cow in the Study}

A cow with a case of CM was identified by the milkers on the participating dairy farms. After identification of the case, the animal was segregated and further observations were performed by trained farm staff. The inclusion form for each case of CM was completed. Only cows that met all eligibility criteria were entered into the study. When a cow met all eligibility criteria, the cow was randomized to 1 of the 2 treatments. Randomization took place through the opening of a numbered envelope. The envelope contained detailed treatment instructions and treatment forms. Before treating a cow, the teat of the affected quarter was thoroughly disinfected and 3 streams of milk from the affected quarter were discarded. A milk sample was taken and immediately placed on ice and eventually stored in the on-farm freezer. Milk samples were collected regularly (at least monthly) and transported on ice to the laboratories of Quality Milk Production Services (Ithaca, NY). After the sample was taken, the teat end was disinfected again and treated with the allocated treatment. The cow was marked as antibiotic positive using a leg band. The treatment form was then completed and initialed. Treatments were completed at the next milking (cephapirin) or during the next days (ceftiofur). For each treatment, a dated and signed treatment form was completed. At approximately $10 \mathrm{~d}$ $( \pm 2 \mathrm{~d})$ and $17 \mathrm{~d}( \pm 2 \mathrm{~d})$ after the onset of treatment, a milk sample was collected from the affected quarter using the previously described procedures. This relatively short interval between the end of treatment and first sample was chosen to accommodate the generally short duration of Escherichia coli IMI (Pyörälä et al., 1994), thereby preventing the risk of new infections to distort the observed cure risks (Schukken et al., 2011). At the 2 posttreatment sampling moments, a clinical score was also obtained. At any point during enrollment in the trial, the farm owner or herd manager was allowed to withdraw a cow from the study and treat her with additional or different treatments. Before any treatment outside the defined protocols was applied, a milk sample was collected and a clinical score was completed on the cow. In such cases, an adverse event form was completed by the herd manager, dated, and initialed.

\section{Bacteriological Culture}

Approximately $0.01 \mathrm{~mL}$ of milk was streaked on trypticase soy agar containing 5\% sheep blood and $0.1 \%$ esculin (PML Microbiologicals, Mississauga, ON, Canada) and plates were incubated aerobically at $37^{\circ} \mathrm{C}$ for $48 \mathrm{~h}$. After observation of colony morphology and hemolytic patterns on blood agar, isolates were examined further by means of $3 \% \mathrm{KOH}$, Gram staining of organisms, catalase and oxidase testing, and additional biochemical and metabolic evaluations as needed. Gram-negative organisms were identified by colony morphology on MacConkey's agar (National Mastitis Council, 1999).

\section{Primary and Secondary Outcomes}

Primary outcomes were bacteriological and clinical cure. Secondary outcomes were days in the study; this parameter reflects the percentage of cows that were removed by the owner from the study. Bacteriological cure was defined as cure in a quarter that was infected 
at the start of treatment and where the organism that was identified at the start of treatment was not present in any of the 2 posttreatment samples. If a cow was removed from the trial after enrollment and initial treatment by the producer for reason of insufficient progress during the follow-up period, the affected quarter was sampled before any other treatment. In such situations, the case was considered a failure of both bacteriological and clinical cure. The reason that such cases were considered a failure for both clinical and bacteriological cure is that the animal clearly did not respond well to the assigned treatment and it is assumed that the reason for this was an inability of the treatment to resolve the intramammary infection. The analysis was therefore based on the "intention-to-treat" set of animals; that is, all randomized animals that received an initial treatment were included in the analysis (O'Connor et al., 2010). If no follow-up samples were taken for other reasons than insufficient progress (such as "forgot to take a sample") for the 2 posttreatment sampling times, the case was considered ineligible for evaluation of bacteriological cure but could still qualify for evaluation of clinical cure.

Clinical cure was defined as the presence of normal milk and a normal gland on the 2 posttreatment evaluation days, approximately 10 and $17 \mathrm{~d}$ after the start of treatment. If a cow was taken off the trial during the follow-up period, the case was considered a failure of clinical cure using the same arguments as mentioned previously for bacteriological cure.

Survival in the study was evaluated by determining the end of study for each enrolled case. A cow fully survived in the study if she went through all treatments and all posttreatment samplings. When a cow was taken off the study for reasons identified by the herd manager, the day that she was taken off the study was noted and used as the endpoint for this analysis.

\section{Statistical Analysis}

Statistical analysis of the primary outcomes was done using generalized linear mixed models, taking into account important covariates such as the parity of the cow, days in milk at the time of treatment, and quarter location. The analysis was corrected for within-farm clustering using random farm effects. The primary predictor variable of interest was the treatment group. The logistic regression model that was used for bacteriological cure (model [1]) and clinical cure was

$$
\begin{gathered}
\text { Logit }(\text { cure })=\text { intercept }+ \text { parity }+ \text { days in milk } \\
+ \text { treatment }+ \text { farm }(\text { random })+\text { error }
\end{gathered}
$$

where cure is either bacteriological or clinical cure, parity is parity of the enrolled cow, days in milk is days since calving of the enrolled cow categorized in sets of $100 \mathrm{~d}$, treatment is a binary variable indicating either cephapirin or ceftiofur, and farm is a set of indicator variables for farm.

A second model was used to evaluate the effect of bacterial group (gram-positive vs. gram-negative bacteria) on cure (model [2]). In this model, bacterial group and an interaction of bacterial group with treatment was added to the previously shown model. Least squares means were calculated from the models and used to calculate the difference between treatments. Confidence intervals of the treatment difference were calculated using the least squares means from the regression models and the standard deviation (SD) of the treatment difference estimated from the variance (Var) of the obtained treatment-specific least squares means:

$$
\begin{aligned}
& S D\left[P_{\text {cure }}(\text { cephapirin })-P_{\text {cure }}(\text { ceftiofur })\right]= \\
& \sqrt{\operatorname{Var}\left[P_{\text {cure }}(\text { cephapirin })\right]+\operatorname{Var}\left[P_{\text {cure }}(\text { ceftiofur })\right]} .
\end{aligned}
$$

Time in the study was evaluated using Kaplan-Meier survival curve estimation. The difference in the survival curve was evaluated using the Log-Rank statistic. For all analysis, a $P$-value of 0.05 was used. All analyses were done in SAS version 9.3 (SAS Institute, 2009) using PROC GLIMMIX and PROC LIFETEST.

\section{RESULTS}

\section{Descriptive Results}

Clinical mastitis cases were enrolled on 7 dairy farms in New York State that met the farm eligibility criteria. Farm characteristics of the farms enrolling cases are shown in Table 1. These 7 farms contributed a total of 321 cases to the study. After reviewing the data after the trial, 25 of these contributed cases were considered ineligible for further analysis, resulting in 296 enrolled cases. The reasons for ineligibility were not related to study outcome or treatment group and included failure to adhere to the treatment protocol (e.g., the use of 5 instead of 2 treatments with cephapirin), failure to collect the initial milk sample, and loss of trial records. In any of these situations, a valid case evaluation was impossible. The final data set used for analysis included 296 enrolled cases that met the "intention to treat" criterion. We observed no significant differences in age, DIM, or quarter location between the 2 treatment groups ( $P>0.20$ for all comparisons). The IMI status at the time of first treatment for all eligible cases is shown in Table 2. 
Table 1. Basic description upon entering the study of 296 enrolled coliform mastitis cases on 7 commercial dairy farms (A to G) in New York State

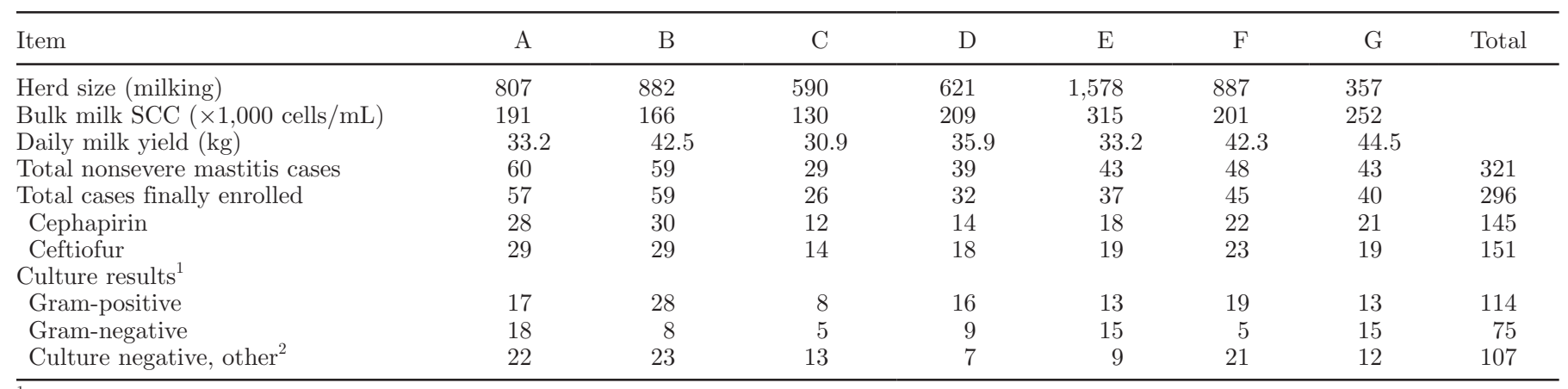

${ }^{1}$ Culture results are from the pretreatment milk sample.

${ }^{2}$ Culture results that fall in this category are defined in Table 2 .

\section{Bacteriological Cure}

Cases were only eligible for bacteriological cure when the treated quarter was infected at the time of entry into the study. From Table 2, it can be seen that this was the case for 193 cases, 96 in the ceftiofur group and 97 in the cephapirin treatment group. Bacteriological cure was observed in 130 of the 193 cases (67\%): 71 out 97 in the ceftiofur group $(73 \%)$ and 59 out of 96 $(61 \%)$ in the cephapirin group. Bacteriological cure by initial bacteriological status and by treatment group is shown in Figure 2. When the results were separated for gram-negative and gram-positive bacteria, the difference between ceftiofur and cephapirin was virtually zero in gram-positive bacteria (67\% cure for ceftiofur

Table 2. Bacteriological status of the 296 enrolled cases at the time of detection of clinical mastitis

\begin{tabular}{|c|c|c|}
\hline IMI status at detection & $\begin{array}{c}\text { Cephapirin } \\
(\mathrm{n}=145)\end{array}$ & $\begin{array}{r}\text { Ceftiofur } \\
(\mathrm{n}=151)\end{array}$ \\
\hline$\overline{\text { Staphylococcus aureus }}$ & 6 & 4 \\
\hline CNS & 5 & 4 \\
\hline Escherichia coli & 19 & 27 \\
\hline Klebsiella spp. & 10 & 14 \\
\hline Streptococcus dysgalactiae & 23 & 19 \\
\hline Streptococcus uberis & 10 & 14 \\
\hline Other $\operatorname{cocci}^{1}$ & 12 & 7 \\
\hline Pasteurella & 1 & 1 \\
\hline Proteus spp. & 1 & 0 \\
\hline Yeast $^{2}$ & 1 & 2 \\
\hline Trueperella pyogenes & 5 & 4 \\
\hline Gram-positive bacilli & 1 & 0 \\
\hline Other Enterobacteriaceae & 0 & 1 \\
\hline Citrobacter spp. & 1 & 0 \\
\hline Prototheca spp. ${ }^{2}$ & 1 & 0 \\
\hline Culture negative $^{2}$ & 35 & 47 \\
\hline Contaminated sample ${ }^{2}$ & 14 & 7 \\
\hline
\end{tabular}

${ }^{1}$ Other cocci include esculin-positive cocci, including non-Strep. uberis streptococci, Enterococcus spp., and Lactococcus spp. These organisms were not further speciated.

${ }^{2}$ Included in the "Culture negative, other" category in Table 1. vs. $68 \%$ for cephapirin), but the difference in bacteriological cure was greater for gram-negative bacteria (79\% for ceftiofur vs. $50 \%$ for cephapirin).

Mixed model logistic regression of bacteriological cure resulted in a numerically better cure risk in ceftiofurtreated cases compared with cephapirin-treated cases (Table 3); the least squares means estimates of cure were $74 \%$ and $62 \%$, respectively. The difference between the 2 treatments, however, was not statistically significant $(P=0.08)$. The results of the final logistic regression model are shown in Table 3 . The most important parameter in bacteriological cure model [1] was the odds ratio for treatment, which indicated that bacteriological cure due to cephapirin was approximately 0.57 times that for ceftiofur. This odds ratio was not significantly different from 1 as the confidence interval was between 0.30 and 1.07. The results for bacteriological cure model [2] showed a significant interaction of treatment and gram-negative infection status. Animals with a gram-negative infection treated with cephapirin showed a significantly lower risk of cure compared with those treated with ceftiofur. Animals with a grampositive infection showed identical risk of cure for both treatments, and a true noninferiority of cephapirin relative to ceftiofur was shown. Calculation of the cure difference was done with the results of model [1] and model [2], and the cure differences with $95 \%$ CI are shown in Figure 3.

\section{Clinical Cure}

Clinical cure was observed for 184 out of 296 enrolled cases $(62 \%)$ and was equal between the 2 treatment groups, with both showing a clinical cure of $62 \%$. Clinical cure was $71 \%$ for the quarters with no discernible IMI at enrollment, $63 \%$ for gram-positive bacteria, and $49 \%$ for gram-negative bacteria. Differences in clinical cure for gram-positive bacteria between the treatment 


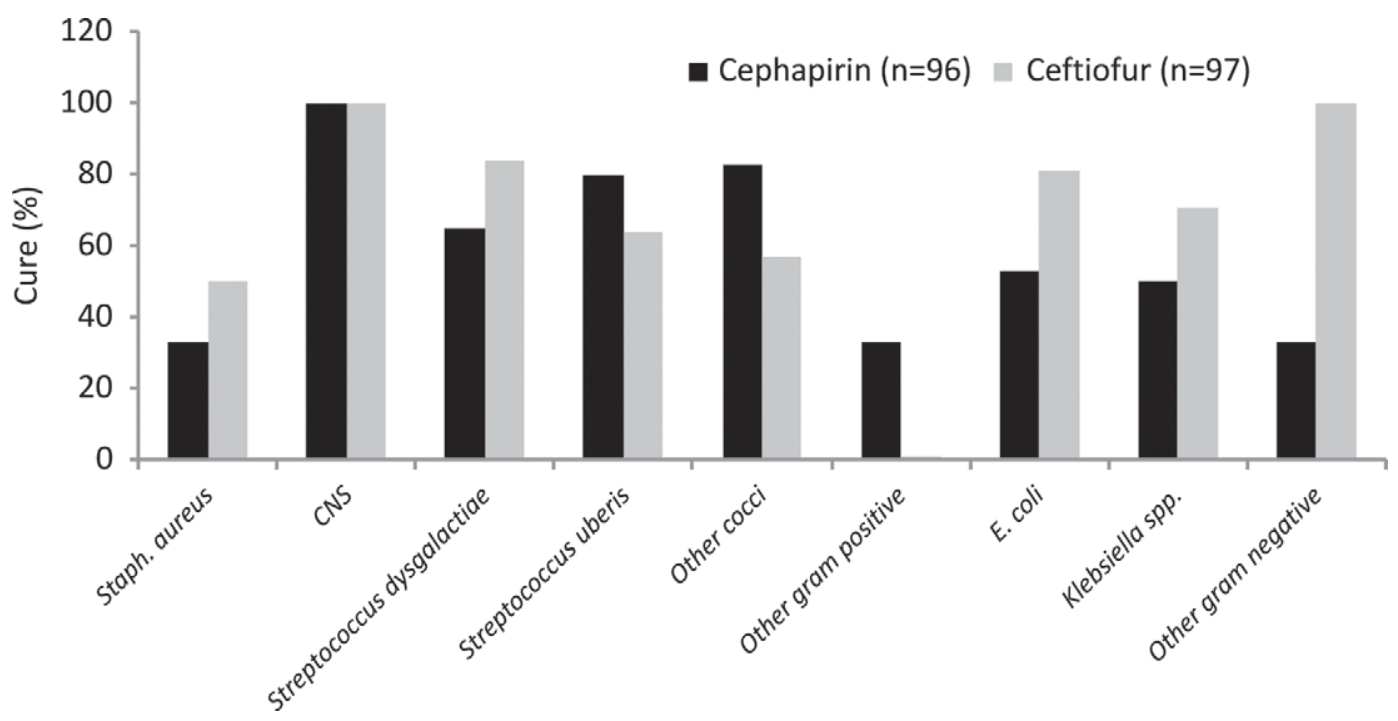

Figure 2. Bacteriological cure for quarters treated with ceftiofur or cephapirin. Cure is shown for the main bacterial species and for the remaining bacteria as either other gram-positive or other gram-negative. Staph. $=$ Staphylococcus; E. coli = Escherichia coli.

groups were small $(62 \%$ for ceftiofur-treated cases and $65 \%$ for cephapirin-treated cases) and somewhat larger for gram-negative bacteria ( $44 \%$ for ceftiofur-treated cases and $56 \%$ for cephapirin-treated cases). The relationship between bacteriological cure and clinical cure was strong. In bacteriologically cured cases, $77 \%$ also showed clinical cure, whereas the bacteriologically noncured cases showed only $39 \%$ clinical cure.

Mixed model logistic regression of clinical cure resulted in a numerically identical cure risk in ceftiofur- treated cases compared with cephapirin-treated cases; the least squares means estimate of cure was $63 \%$ for both treatments. The difference between the 2 treatments was not statistically significant $(P=0.95)$. The results of the final logistic regression model are shown in Table 3. The most important parameter in this table is the odds ratio for treatment, showing that clinical cure was approximately 1.02 times higher for ceftiofurtreated cows compared with cephapirin-treated cows. This odds ratio was not significantly different from 1

Table 3. Mixed model logistic regression results on bacteriological cure (BC) models and clinical cure model

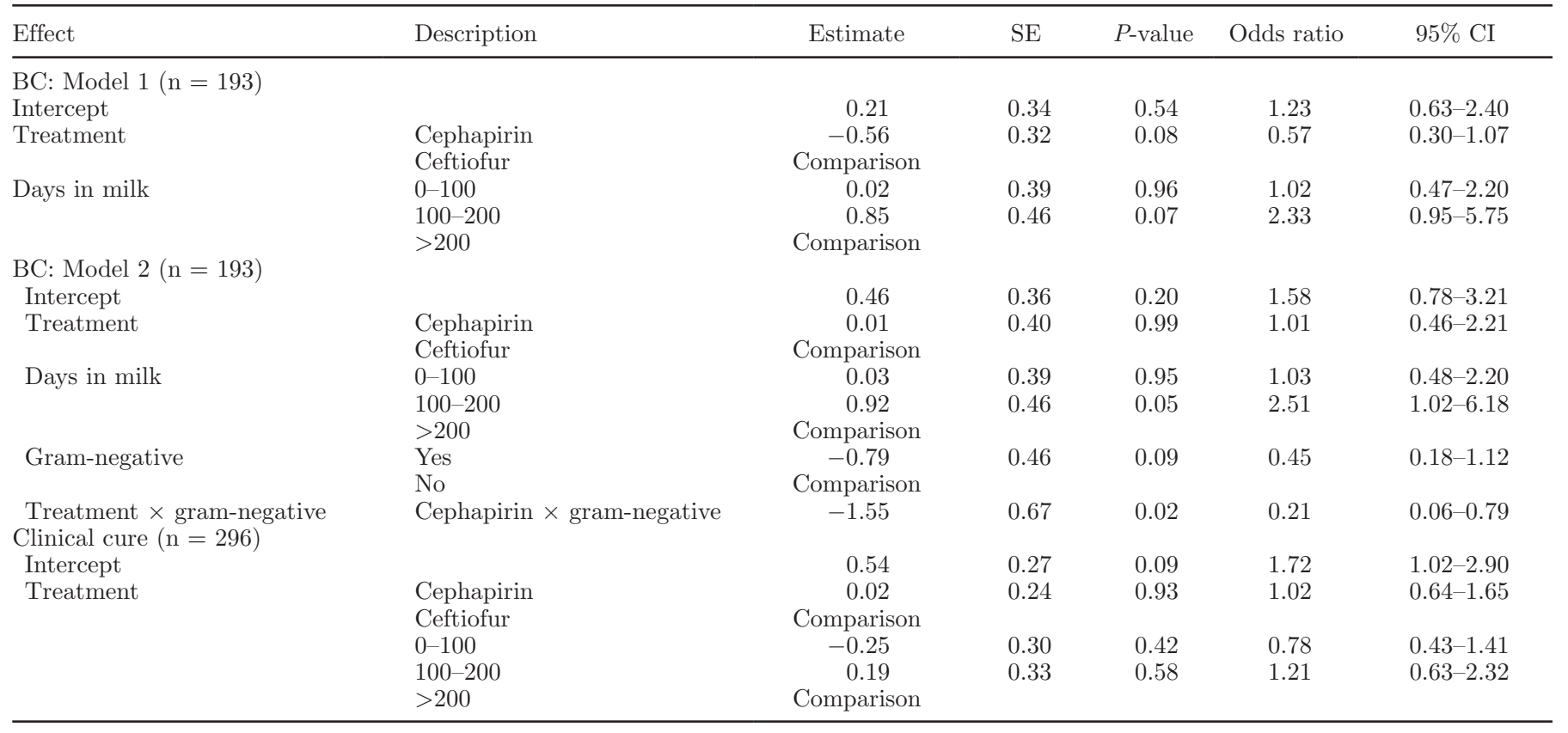




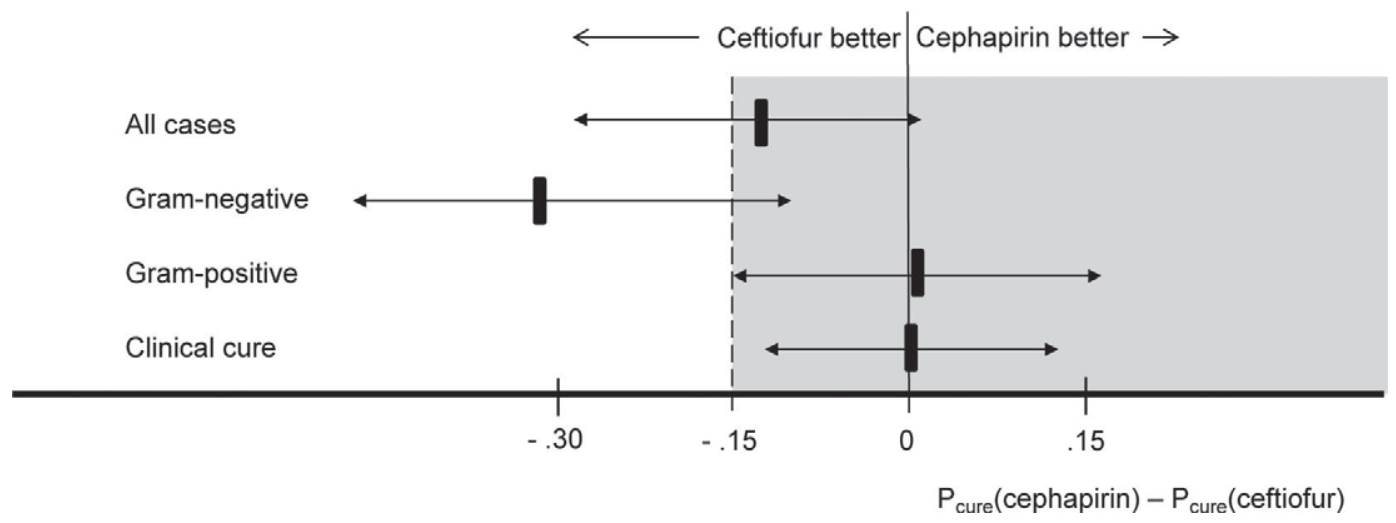

Figure 3. Graphical representation of the main outcomes of this noninferiority trial. Black block indicates point-estimate of difference in cure between cephapirin and ceftiofur; arrowheads indicate $95 \% \mathrm{CI}$; shaded area indicates zone of noninferiority. All cases = bacteriological cure of all cases: the CI spans both zero and the noninferiority margin $(-\Delta)$, noninferiority is inconclusive, and no significant difference exists between the 2 treatments. Gram-negative = bacteriological cure in gram-negative cases: the CI spans $-\Delta$ but not zero, ceftiofur is significantly better, but noninferiority is inconclusive. Gram-positive $=$ bacteriological cure in gram-positive cases: the CI spans zero but not $-\Delta$, noninferiority is proven, and no significant difference exists between cephapirin and ceftiofur. Clinical cure $=$ clinical cure: the CI spans 0 but not $-\Delta$, noninferiority is proven, and no significant difference exists between cephapirin and ceftiofur.

as the confidence interval was between 0.64 and 1.65 . The difference in clinical cure was calculated from the results of the logistic regression and the point estimate and $95 \%$ CI of the cure difference between the 2 treatments is shown in Figure 3.

\section{Time in the Study}

Time in the study was measured as the time between study enrollment and the time that the animal was taken off the study, either because all observations were completed or because an adverse effect or a decision by the herd manager resulted in taking the cow off the study. A total of 48 cows were taken off the study (16\%): 18 for the ceftiofur group (12\%) and 30 for the cephapirin group (21\%). One farm (C) removed a high proportion $(50 \%)$ of enrolled animals from the study compared with the other study farms. On farm C, 10 of 12 cephapirin-treated animals and 3 of 14 ceftiofurtreated animals were removed. All the animals that were taken off the study were considered as bacteriological and clinical noncures (see earlier). Among the cows that were initially infected with gram-positive bacteria, $18(16 \%)$ were taken off the study; for animals initially infected with gram-negative bacteria, 20 were taken off the study (27\%). The survival curve for cows to remain in the study is shown in Figure 4. The increased exit from the study in cephapirin-treated animals is clear from this graph and appeared to occur in the first week of the treatment; thereafter, the rate of exit between the 2 treatment groups was virtually identical. Log-rank analysis of the data indicated no significant difference between the 2 treatment groups in time to exit from the study $\left(\chi^{2}=0.76, P=0.38\right)$. When the same analysis was done to compare gram-negative cases with all other cases, we observed a significant increased rate of exit for gram-negative cases in the Log-rank test $\left(\chi^{2}=\right.$ 7.64, $P=0.0057)$. Among the gram-negative cases, no statistically significant difference was observed between cows treated with ceftiofur compared with cephapirin $\left(\chi^{2}=0.23, P=0.63\right)$.

\section{DISCUSSION}

We performed a positive-control randomized trial to evaluate the difference in treatment efficacy of 2 intramammary treatment protocols in nonsevere CM. The study objective was to evaluate 2 treatment protocols that were used according to label. This implied that treatment duration was not identical and was $12 \mathrm{~h}$ for cephapirin and $5 \mathrm{~d}$ for ceftiofur. Although cephapirin is only applied in a 12-h time period, the formulation is such that it produces antimicrobial concentrations $>0.1 \mu \mathrm{g} / \mathrm{mL}$ for 36 to $48 \mathrm{~h}$ (Gorden et al., 2013). The most important findings are summarized in Figure 3. The 2 treatment groups did not differ in clinical cure: both groups showed a clinical cure of approximately $62 \%$ and noninferiority of cephapirin relative to ceftiofur was shown. The risk of bacteriological cure was numerically higher in ceftiofur-treated cases compared with cephapirin-treated cases, estimated at $74 \%$ and $62 \%$, respectively. However, this difference was not statistically significant and noninferiority was inconclusive due to spanning of the CI of the noninferiority margin. This study was designed such that there was sufficient power in the study to detect a difference between the 


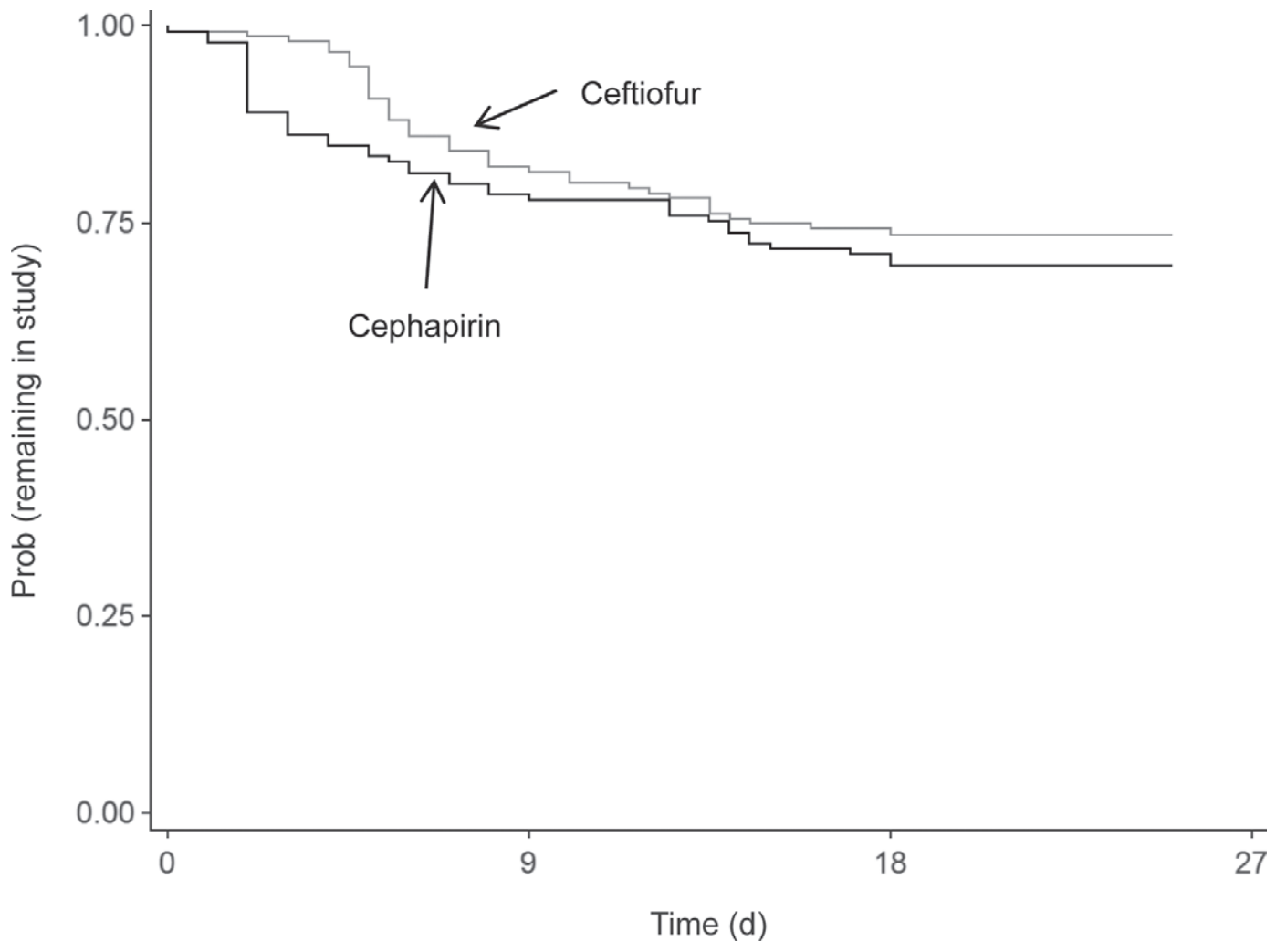

Figure 4. Kaplan-Meier survival curves of the probability of remaining in the study for cows in the 2 treatment groups: cephapirin and ceftiofur.

2 treatment groups if the real difference was at least $15 \%$. Because the observed difference was smaller than this critical value, the statistical analysis resulted in a nonsignificant finding and we essentially lacked power to identify a significant difference of the observed size. This is obvious in Figure 3, where the CI of the difference in cure spans both zero and the noninferiority margin, $\Delta$. The test of noninferiority was therefore inconclusive. Obviously, the choice of the noninferiority margin will affect the sample size and potential conclusions from a study. The noninferiority margin that we chose is one generally used in mastitis treatment trials (Schukken and Deluyker, 1995).

When the difference between treatments was analyzed further, it became obvious that a large difference in cure was observed when gram-negative mastitis cases were treated. This is shown in more detail in Figure 3. In cases of gram-negative mastitis, the difference in cure between cephapirin and ceftiofur is approximately -0.32 and the CI does not span 0 but does span the noninferiority margin of -0.15 . As previously reported, gram-negative organisms in general (Pfeifer et al., 2010) and mastitis gram-negatives specifically (GuérinFaublée et al., 2003) are more often resistant to first- generation cephalosporins, but generally sensitive to third-generation cephalosporins (e.g., Bengtsson et al., 2009). From the findings in our trial, we conclude that cephapirin has a significantly lower cure risk of gramnegative cases but noninferiority is inconclusive. In contrast, the difference in cure between the treatments for gram-positive cases was very small, at 0.01 , and the confidence interval did not span the noninferiority margin and did span zero. From these findings, we can conclude that cephapirin is noninferior to ceftiofur for the treatment of gram-positive cases of clinical mastitis. The absolute risk of cure of gram-positive organisms was approximately $70 \%$, about 10 percentage points lower than the cure risk reported by Apparao et al. (2009). The strict adherence to the "intention to treat" principle in our study, as suggested by the REFLECT (Reporting guidElines For randomized controLled trials for livestoCk and food safeTy) statement (O'Connor et al., 2010), may have resulted in this apparent difference in cure risk. Despite the difference in bacteriological cure risk between the 2 treatments, no difference between the treatment groups was observed for clinical cure. In both treatment groups, the clinical cure risk was $63 \%$. A difference was observed in clinical 


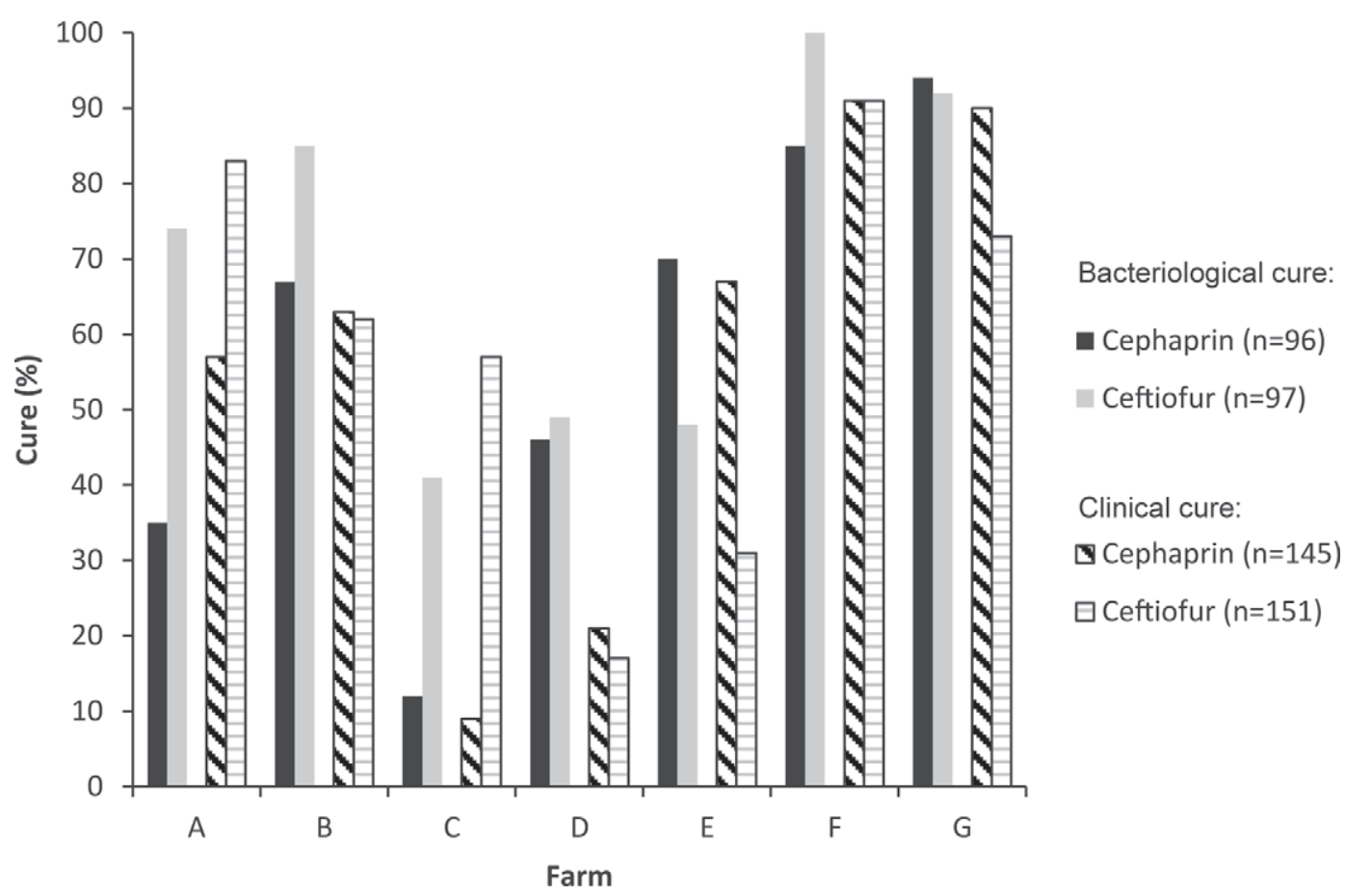

Figure 5. Bacteriological (Model 1, Table 3) and clinical cure (\%) for the 2 treatment protocols using cephapirin and ceftiofur on the 7 farms (A to $\mathrm{G}$ ) included in this study.

cure between gram-positive (higher) and gram-negative (lower) cases of nonsevere clinical mastitis but no significant $(P>0.2)$ or clinically important differences between the treatment groups were observed. As shown in Figure 3, the difference in cure risk between the 2 treatments was zero and the CI for this estimate did not span the noninferiority margin. From this, we may conclude that cephapirin is noninferior to ceftiofur with regard to clinical cure. We evaluated cure at 10 and $17 \mathrm{~d}$ after the initiation of treatment, and this relatively short interval between treatment and evaluation of cure may have lowered the overall clinical cure risk relative to studies in which treatment evaluations are performed later.

Initial rate of exit from the trial was higher in the cephapirin-treated cases compared with the ceftiofurtreated cases. This study was not set up as a blind trial, and herd managers were aware whether a cow was treated for only $1 \mathrm{~d}$ (cephapirin) or for $5 \mathrm{~d}$ (ceftiofur). This may have biased the herd managers, particularly on farm C (see Figure 5), toward further treatment of cephapirin-treated cows, thereby defining these cases as failures with regard to bacteriological and clinical cure.

The differences in bacteriological cure between ceftiofur and cephapirin should be weighed with the cost and effort of treatment and discarded milk when making decisions on treatment protocols (Steeneveld et al., 2011). When using the results of this study to infer to actual dairy farm circumstances, it is important to review the inclusion criteria used in this study. For example, cases occurring within $30 \mathrm{~d}$ of a previous case were not included in this study. From the data obtained in this study, several potential treatment protocols or treatment flowcharts may be developed. Particularly, farms with rapid access to culture results of clinical cases would benefit from making treatment protocols that are specific to the identified microorganism. Although we did not perform a formal cost-benefit analysis, some herds that do not use a culture-based approach for the treatment of CM may see an economic benefit from selecting cephapirin, with the shorter duration of nonsaleable milk ( 4.5 vs. 8 d), as the first treatment of choice. This would be particularly true in herds that have an average or below-average incidence of gram-negative organisms causing CM. The information obtained in this study and others may guide herd advisors to develop herd-specific protocols.

\section{CONCLUSIONS}

We conducted a large, multi-herd, noninferiority study comparing a 1-d treatment of a first-generation cephalosporin (cephapirin) with a 5-d treatment of a third-generation cephalosporin (ceftiofur). Cephapirin 
was not inferior with regard to clinical cure and bacteriological cure of gram-positive bacteria. However, ceftiofur showed a significantly higher bacteriological cure of gram-negative infections associated with mild and moderate CM. These and similar results may be the basis for developing farm-specific CM treatment protocols.

\section{ACKNOWLEDGMENTS}

We acknowledge the support of the New York State dairy farmers participating in this study. We acknowledge Boehringer Ingelheim Vetmedica Inc. (St. Joseph, MO) for providing financial support of this study.

\section{REFERENCES}

Apparao, M. D., P. L. Ruegg, A. Lago, S. Godden, R. Bey, and K. Leslie. 2009. Relationship between in vitro susceptibility test results and treatment outcomes for gram-positive mastitis pathogens following treatment with cephapirin sodium. J. Dairy Sci. 92:2589-2597.

Barkema, H. W., Y. H. Schukken, T. J. G. M. Lam, M. L. Beiboer, H. Wilmink, G. Benedictus, and A. Brand. 1998. Incidence of clinical mastitis in dairy herds grouped in three categories by bulk milk somatic cell counts. J. Dairy Sci. 81:411-419.

Bengtsson, B., H. E. Unnerstad, T. Ekman, K. Artursson, M. NilssonOst, and K. P. Waller. 2009. Antimicrobial susceptibility of udder pathogens from cases of acute clinical mastitis in dairy cows. Vet. Microbiol. 136:142-149.

Bradley, A. J., and M. J. Green. 2009. Factors affecting cure when treating bovine clinical mastitis with cephalosporin-based intramammary preparations. J. Dairy Sci. 92:1941-1953.

Deluyker, H. A., S. T. Chester, and S. N. Van Oye. 1999. A multilocation clinical trial in lactating dairy cows affected with clinical mastitis to compare the efficacy of treatment with intramammary infusions of a lincomycin/neomycin combination with an ampicillin/cloxacillin combination. J. Vet. Pharmacol. Ther. 22:274-282.

Erskine, R. J., P. C. Bartlett, J. L. VanLente, and C. R. Phipps. 2002. Efficacy of systemic ceftiofur as a therapy for severe clinical mastitis in dairy cattle. J. Dairy Sci. 85:2571-2575.

Erskine, R. J., R. J. Eberhart, L. J. Hutchinson, S. B. Spencer, and M. A. Campbell. 1988. Incidence and types of clinical mastitis in dairy herds with high and low somatic cell counts. J. Am. Vet. Med. Assoc. 192:761-765.

European Medicines Agency. 2009. EMEA/CVP/344/99: Guideline for the conduct of efficacy studies for intramammary products for use in cattle. Accessed Jul. 26, 2013. http://www.emea.europa. eu/docs/en_GB/document_library/Scientific_guideline/2009/10/ WC500004501.pdf.

Gorden, P. J., M. van der List, F. D. Lehman, R. K. Lantz, and P. D. Constable. 2013. Elimination kinetics of cephapirin sodium in milk after an 8-day extended therapy program of daily intramammary infusion in healthy lactating Holstein-Friesian cows. J. Dairy Sci. 96:4455-4464.

Gröhn, Y. T., D. J. Wilson, R. N. González, J. A. Hertl, H. Schulte, G. Bennett, and Y. H. Schukken. 2004. Effect of pathogen-specific clinical mastitis on milk yield in dairy cows. J. Dairy Sci. 87:3358-3374.

Guérin-Faublée, V., G. Carret, and P. Houffschmitt. 2003. In vitro activity of 10 antimicrobial agents against bacteria isolated from cows with clinical mastitis. Vet. Rec. 152:466-471.

Hornish, R. E., and S. F. Kotarski. 2002. Cephalosporins in veterinary medicine - Ceftiofur use in food animals. Curr. Top. Med. Chem. $2: 717-731$.
Lago, A., S. M. Godden, R. Bey, P. L. Ruegg, and K. Leslie. 2010. The selective treatment of clinical mastitis based on on-farm culture results: I. Effects on antibiotic use, milk withholding time, and short-term clinical and bacteriologic outcomes. J. Dairy Sci. 94:4441-4456.

McDougall, S. 2010. A randomised, non-inferiority trial of a new cephalonium dry-cow therapy. N. Z. Vet. J. 58:45-58.

McDougall, S., D. G. Arthur, M. A. Bryan, J. J. Vermunt, and A. M. Weir. 2007. Clinical and bacteriological response to treatment of clinical mastitis with one of three intramammary antibiotics. N. Z. Vet. J. 55:161-170.

National Mastitis Council. 1999. Laboratory Handbook on Bovine Mastitis. National Mastitis Council, Madison, WI.

O'Connor, A. M., J. M. Sargeant, I. A. Gardner, J. S. Dickson, M. E. Torrence, C. E. Dewey, I. R. Dohoo, R. B. Evans, J. T. Gray, M. Greiner, G. Keefe, S. L. Lefebvre, P. S. Morley, A. Ramirez, W. Sischo, D. R. Smith, K. Snedeker, J. Sofos, R. L. Buchanan, J. S. Dickson, R. B. Evans, B. Fergen, I. A. Gardner, J. T. Gray, M. Greiner, G. Keefe, K. Lechtenberg, S. L. Lefebvre, P. S. Morley, A. Ramirez, B. J. Rauch, S. C. Read, W. Sischo, D. R. Smith, K. Snedeker, J. N. Sofos, M. P. Ward, and R. W. Wills. 2010. The REFLECT statement: Methods and processes of creating reporting guidelines for randomized controlled trials for livestock and food safety by modifying the CONSORT statement. Zoonoses Public Health 57:95-104.

Olde Riekerink, R. G., H. W. Barkema, D. F. Kelton, and D. T. Scholl. 2008. Incidence rate of clinical mastitis on Canadian dairy farms. J. Dairy Sci. 91:1366-1377.

Pfeifer, Y., A. Cullik, and W. Witte. 2010. Resistance to cephalosporins and carbapenems in Gram-negative bacterial pathogens. Int. J. Med. Microbiol. 300:371-379.

Piaggio, G., D. R. Elbourne, D. G. Altman, S. J. Pocock, and S. J. W. Evans. 2006. Reporting of non-inferiority and equivalence randomized trials: An extension of the CONSORT statement. JAMA 295:1152-1160.

Powers, J. H. 2008. Non-inferiority and equivalence trials: Deciphering similarity of medical interventions. Stat. Med. 27:343-352.

Pyörälä, S., L. Kaartinen, H. Käck, and V. Rainio. 1994. Efficacy of two therapy regimens for treatment of experimentally induced Escherichia coli mastitis in cows. J. Dairy Sci. 77:453-461.

Roberson, J. R. 2012. Treatment of clinical mastitis. Vet. Clin. North Am. Food Anim. Pract. 28:271-288.

Roberson, J. R., L. D. Warnick, and G. Moore. 2004. Mild to moderate clinical mastitis: Efficacy of intramammary amoxicillin, frequent milk-out, a combined intramammary amoxicillin, and frequent milk-out treatment versus no treatment. J. Dairy Sci. 87:583-592.

SAS Institute. 2009. SAS software. Version 9.2. SAS Institute Inc., Cary, NC

Schukken, Y. H., G. J. Bennett, M. J. Zurakowski, H. L. Sharkey, B. J. Rauch, M. J. Thomas, B. Ceglowski, R. L. Saltman, N. Belomestnykh, and R. N. Zadoks. 2011. Randomized clinical trial to evaluate the efficacy of a 5-day ceftiofur hydrochloride intramammary treatment on nonsevere gram-negative clinical mastitis. J. Dairy Sci. 94:6203-6215.

Schukken, Y. H., and H. A. Deluyker. 1995. Design of field trials for the evaluation of antibacterial products for therapy of bovine clinical mastitis. J. Vet. Pharmacol. Ther. 18:274-283.

Scientific Advisory Group on Antimicrobials of the Committee for Medicinal Products for Veterinary Use. 2009. Reflection paper on the use of third and fourth generation cephalosporins in food producing animals in the European Union: Development of resistance and impact on human and animal health. J. Vet. Pharmacol. Ther. $32: 515-533$.

Steeneveld, W., T. van Werven, H. W. Barkema, and H. Hogeveen. 2011. Cow-specific treatment of clinical mastitis: An economic approach. J. Dairy Sci. 94:174-188.

Taponen, S., K. Dredge, B. Henriksson, A. M. Pyyhtiä, L. Suojala, R. Junni, K. Heinonen, and S. Pyörälä. 2003. Efficacy of intramammary treatment with procaine penicillin $G$ vs. procaine penicillin $\mathrm{G}$ plus neomycin in bovine clinical mastitis caused by penicillin- 
susceptible, gram-positive bacteria-A double blind field study. J. Vet. Pharmacol. Ther. 26:193-198.

US FDA-CVM (Food and Drug Administration Center for Veterinary Medicine). 1996. CVM Guidance for Industry \#49: Target animal safety and drug effectiveness studies for anti-microbial bovine mastitis products (lactating and non-lactating cow products). Accessed Jul. 26, 2013. http://www.fda.gov/AnimalVeterinary/GuidanceComplianceEnforcement/GuidanceforIndustry/ucm053411. htm.

Waage, S. 1997. Comparison of two regimens for the treatment of clinical bovine mastitis caused by bacteria sensitive to penicillin. Vet. Rec. 141:616-620.
Wenz, J. R., G. M. Barrington, F. B. Garry, R. P. Dinsmore, and R. J. Callan. 2001. Use of systemic disease signs to assess disease severity in dairy cows with acute coliform mastitis. J. Am. Vet. Med. Assoc. 218:567-572.

Wenz, J. R., F. B. Garry, and G. M. Barrington. 2006. Comparison of disease severity scoring systems for dairy cattle with acute coliform mastitis. J. Am. Vet. Med. Assoc. 229:259-262.

Wenz, J. R., F. B. Garry, J. E. Lombard, R. Elia, D. Prentice, and R. P. Dinsmore. 2005. Efficacy of parenteral ceftiofur for treatment of systemically mild clinical mastitis in dairy cattle. J. Dairy Sci. 88:3496-3499. 